\title{
Is the common cold a clinical entity or a cultural concept?*
}

\section{Ron Eccles}

Common Cold Centre and Healthcare Clinical Trials, Cardiff School of Biosciences, Cardiff University, United Kingdom
Rhinology 51: 000-000, 2013 DOl:10.4193/Rhino 12.123

*Received for publication: July 18, 2012

Accepted: November 15, 2012

\section{SUMMARY}

Common cold is the most common infectious disease of mankind and the term is widely used in the clinical literature as though it were a defined clinical syndrome. Clinical studies on this syndrome often use elaborate symptom scoring systems to diagnose a common cold. The symptom scores are based on a study conducted over 50 years ago to retrospectively diagnose experimental cold and this method cannot be applied to diagnosis of common cold in the community. Diagnosis of the common cold by virology is not feasible because of the number of viruses and the variability in the disease states caused by the viruses. Because of the familiarity of subjects with common cold and the variability in symptomatology it seems a more reasonable approach to use self-diagnosis of common cold for clinical research studies and accept that the common cold is a cultural concept and not a clinical entity.

Key words: Influenza, rhinovirus, clinical trial, symptom scores

\section{Introduction}

The common cold is unlike any other human disease because of two factors: firstly it is arguably the most common human infectious disease and secondly, it is one of the most complex diseases because of the number of viruses that cause the familiar syndrome of sneezing sore throat, runny nose, and nasal congestion" (1). The term 'common cold' is widely used in the medical literature. Pubmed lists around 1200 articles with common cold in the title, with 33 of these appearing in 2011, but the term 'common cold' is not a clinical or scientific term with an agreed definition, but is a poorly defined term that has been used for centuries by the lay person to describe a common illness. Modern experts on common cold define common cold as "a culturally accepted constellation of upper respiratory symptoms" (2).
In medicine it is important to be able to diagnose with some certainty the disease that is under investigation. This clinical rigour does not apply to the diagnosis of 'common cold', as in many studies the diagnosis of the disease is left entirely to the patient and in other studies, a system of symptom scores may be used, that appear to be scientific, but in reality they do not have any validation or scientific basis in diagnosing the disease. If the common cold is a clinical entity then it should be possible to define the condition in terms of symptomatology or virology but if it is a cultural concept then self-diagnosis by the patient is a more reasonable approach for diagnosis.

\section{Definition of the disease state}

To be able to diagnose a disease it is first necessary to define the disease, but this is not easy for common cold. Most definitions 
refer to an acute upper respiratory tract viral infection, but when it comes to selecting patients for a clinical trial on common cold treatments these definitions are not so useful.

The Merck Manual (1999) defines a common cold as: "An acute, usually afebrile, viral infection of the respiratory tract, with inflammation in any or all airways, including the nose, paranasal sinuses, throat, larynx and sometimes the trachea and bronchi. Clinical symptoms and signs are non specific" (3).

Blacks Medical Dictionary (2002) defines a cold as: "An infection by any one of around 200 viruses, with about half the common cold infections being caused by rhinoviruses" (4).

European position paper on rhinosinusitis and nasal polyps (2012) defines a common cold as: "Common cold/acute viral rhinosinusitis is defined as: duration of symptoms for less than 10 days" $^{\prime(5)}$.

The term 'common cold' was used to describe a common syndrome of symptoms long before the discovery of the viruses responsible for the disease. The disease is therefore self-diagnosed world-wide on the basis of a grouping of familiar symptoms such as sore throat, runny nose, sneezing, and nasal congestion ${ }^{(6)}$. With patients able to self-diagnose a common cold on the basis of symptoms it would be expected that there was some generally accepted clinical symptomatology that could be used to diagnose a common cold.

Problems associated with clinical diagnosis of common cold on the basis of symptomatology

Problems with symptom scores

The symptom scores that are now generally used to diagnose common cold in clinical studies were devised in 1958 by Jackson and colleagues ${ }^{(7)}$. The paper by Jackson et al. ${ }^{(7)}$ has been cited in PubMed (23 Jan 2012) 185 times with six citations in 2011 and it is an important publication as regards the definition of the common cold, and the description of a simple scoring system for upper respiratory tract symptoms. However, the study has several limitations that make its conclusions difficult to apply universally to diagnosis of a common cold.

Firstly, the study used nasal challenge with infected nasal secretions to cause an experimental common cold, and natural infection with common cold viruses may cause a different pattern of symptoms. Viral challenge with cultured viruses is known to cause much milder symptoms than natural colds and some of the induced colds have been described as "too mild to treat" (8). To be fair to Jackson, he never claimed that his study provided more than just a definition of an 'experimental' cold, and the results were never intended to be applied to natural colds in the community.

Secondly, the study used cumulated scores over a six days period to DEFINE a cold and therefore the criteria are not applicable to early DIAGNOSIS of common cold, for example colds of only a few days duration may have a different symptomatology to colds in a late stage at 5 or 6 days. This is acknowledged by Jackson who says that headache, sneezing, chilliness and sore throat were early symptoms that declined after one or two days duration.

Thirdly, the population were young healthy students aged mainly between 20-25 years and the results are likely to be different in infants and in the elderly. Common cold is rarely associated with fever in adults and Jackson states that it is an "afebrile illness" in the adult, whereas fever is commonly associated with common cold in the pre-school age child ${ }^{(9)}$.

Despite the widespread use of 'Jackson scores' in clinical trials on common cold, this scoring system cannot be applied to early diagnosis of naturally occurring colds in patients recruited to clinical trials. Most patients are recruited in the first few days of common cold symptoms and the Jackson scores were developed to retrospectively diagnose experimental colds over a six days period.

Other problems associated with using symptoms to diagnose common cold

Diagnosis of common cold using symptomatology is problematic as the incidence and severity of symptoms vary during the course of a respiratory viral infection, and the severity of the illness may range from a mild almost asymptomatic illness with a few sneezes and little nasal discharge, through severe and disabling feverish illness, right up to a life threatening lower respiratory tract infection such as bronchiolitis in infants. Caution is also needed in diagnosing all cases of mild respiratory symptoms as a common cold, since other common diseases such as measles, mumps and rubella infect the respiratory tract and may present with upper respiratory tract symptoms resembling a common cold ${ }^{(10)}$

The upper respiratory tract has a limited range of physiological responses, and the symptoms associated with physical irritation of the airway, infection and allergy, are all similar, and usually involve, sneezing, runny nose, and nasal congestion. Therefore the responses to air pollution, allergen challenge and viral and bacterial infection all have some similarities, and this makes it difficult to confidently diagnose a common cold solely on the basis of symptoms. As stated above in the definition of common cold given in the Merck Manual: "Clinical symptoms and signs are non specific" (3).

\section{Diagnosis of common cold using virology}

If the diagnosis of common cold is based on virology then it is necessary to identify the virus, and this is not always possible because of the very large number of viruses that can cause common cold. Weber ${ }^{(11)}$ describes the common cold as being caused by the following groups of respiratory viruses: rhinoviruses, respiratory syncytial viruses, parainfluenza viruses, adenoviruses, 
Table1. Diagnosis of common cold in some clinical studies.

\begin{tabular}{|c|c|c|c|c|c|c|c|}
\hline Reference & Type of study & $\begin{array}{l}\text { Participants } \\
\text { and country }\end{array}$ & Age years & Stage of cold & $\begin{array}{c}\text { Patient self } \\
\text { diagnosis }\end{array}$ & $\begin{array}{l}\text { Diagnosis } \\
\text { by symptoms }\end{array}$ & $\begin{array}{l}\text { Diagnosis } \\
\text { by virology }\end{array}$ \\
\hline $\begin{array}{l}\text { Yakoot, M } \\
(2011)^{\prime}\end{array}$ & $\begin{array}{l}\text { Clinical trial } \\
\text { on medicine }\end{array}$ & $\begin{array}{l}62 \\
\text { outpatients of } \\
\text { clinic } \\
\text { Egypt }\end{array}$ & mean 38.0 & $<-36$ hrs & $\begin{array}{l}\text { Not men- } \\
\text { tioned }\end{array}$ & $\begin{array}{l}2 \text { of } 10 \text { symptoms: cough, head- } \\
\text { ache, hoarseness, muscle aches, } \\
\text { nasal discharge, nasal congestion, } \\
\text { scratchy throat, sore throat, sneez- } \\
\text { ing, or an oral temperature }>37.7^{\circ} \mathrm{C}\end{array}$ & NO \\
\hline $\begin{array}{l}\text { Eccles, R } \\
(2010)\end{array}$ & $\begin{array}{l}\text { Clinical trial } \\
\text { on } \\
\text { antiviral nasal } \\
\text { spray }\end{array}$ & $\begin{array}{l}35 \\
\text { University } \\
\text { students and } \\
\text { staff } \\
\text { United } \\
\text { Kingdom }\end{array}$ & mean 19.6 & $<48 \mathrm{hrs}$ & YES & $\begin{array}{l}\text { Score of } 1 \text { or greater for any one } \\
\text { symptoms of sore throat, runny } \\
\text { nose and blocked nose and a total } \\
\text { score of less than } 9 \text { from } 8 \text { symp- } \\
\text { toms: headache, muscle ache, } \\
\text { chilliness, sore throat, runny nose, } \\
\text { blocked nose, cough and sneezing }\end{array}$ & NO \\
\hline
\end{tabular}

metapneumoviruses, boca viruses, corona viruses, and influenza viruses, that in all comprise over 200 respiratory viruses that can cause common cold. Even with the most modern methods used to identify respiratory viruses, in many patients with common cold no virus can be identified, despite the presence of respiratory disease.

In a study on 108 children whose parents thought that the children were developing a cold, and who had at least one respiratory symptom, no virus could be detected in over $40 \%$ of the children ${ }^{(12)}$. Another problem is that respiratory viruses can be identified in $8 \%$ of patients despite no reported or observed symptoms of a respiratory virus illness ${ }^{(13)}$. Weber ${ }^{(11)}$ includes influenza viruses as a cause of common cold and so does Heikkinen (14). When influenza viruses are circulating in the community infections often cause sub-clinical infections and mild afebrile common colds ${ }^{(15)}$.

Virology alone cannot be used to diagnose a common cold as this would mean that those patients with sub-clinical asymptomatic infections would be diagnosed as having a common cold, if a rhinovirus or other common cold virus could be isolated. Also, in many patients with symptomatic colds it would not be possible to identify any virus. Some experts may also exclude influenza infections from being diagnosed as common cold despite the fact that mild common cold like symptoms can be caused by infection with an influenza virus. Common cold viruses also cause a wide range of clinical illness, for example the rhinoviruses, which are closely related to enteroviruses, are often a cause of gastroenteritis ${ }^{(16)}$ and respiratory syncytial viruses are a cause of bronchiolitis in infants and viral pneumonia in the elderly ${ }^{(17)}$ and may be as important as influenza as a cause of death ${ }^{(18)}$. Rhinoviruses and corona viruses have been shown to cause a range of severe illness in hospitalised patients with pneumonia in both children and adults ${ }^{(19)}$.

\section{Current methods of diagnosis of common cold in clinical trials}

As mentioned above, the term 'common cold' is widely used in the clinical and scientific literature, but how is this disease diagnosed? Table 1 provides information on several different approaches to diagnosis. The information provided in Table 1 was chosen to illustrate different methods of diagnosis and does not represent a comprehensive summary of all methods in the 


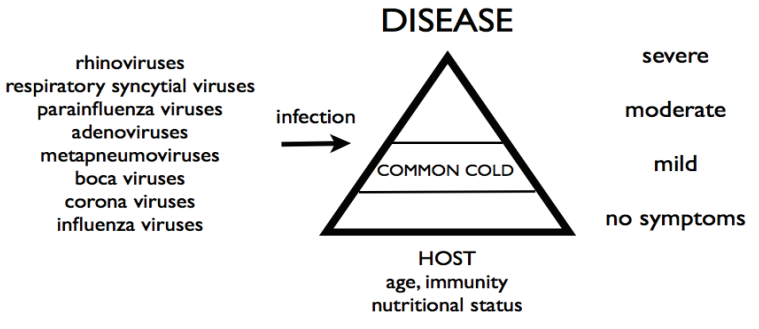

Figure 1. Diagram to illustrate the complexity of common cold. The respiratory viruses infect the host to cause a range of severity of disease that is determined by the age and immunity of the host. The range of disease from mild to moderate is indicated as a 'common cold'. The triangle represents the iceberg of viral infection with most infections causing asymptomatic or mild disease that is not recognised as a cold. Severe symptoms and life threatening infections are also not recognised as a common cold. literature.

What is apparent from the table is that there is no agreement on how to diagnose a common cold and the disease states in each study may be quite different but all are classified as common colds.

The study by Nakata et al. ${ }^{(20)}$ reports a relationship between job satisfaction and common cold. The data on common cold was collected by asking the participants the following question "How many times (episodes) were you infected with common cold in the past 6 months and how many days were symptoms present? The diagnosis of the common cold was therefore left entirely to the participant ${ }^{(20)}$.

The study by Barrett et al. ${ }^{(21)}$ is an important study as it reports the validation of a questionnaire designed to study the impact of common cold on quality of life. A common cold is diagnosed in this study on the basis of Jackson symptom scores and participants were deemed to have a cold if they affirmed they were suffering from a cold of less than 48 hours duration and then fulfilled certain symptom scores as illustrated in Table 1. The scoring system is quite specific but it has never been validated as a means of diagnosing common cold. It is therefore difficult to accept that the questionnaire on common cold can be validated when the method of diagnosing the disease is not validated $^{(21)}$.

The questionnaire validated by Barrett ${ }^{(21)}$ was used by Byun (22) to measure symptom severity in a clinical trial on patients with common cold. In this study, the diagnosis of common cold was made by a physician using the symptom scores shown in Table ${ }^{(22)}$. It is interesting that one of the symptom scores allowed is fever, despite the general agreement in the literature that common cold is not associated with fever in the adult. Similarly the study by Yakoot uses a symptom scores to diagnose common cold and also includes a temperature of $>37.7^{\circ} \mathrm{C}$ as one of the symptoms of common cold ${ }^{(23)}$.

The study by Eccles aimed to recruit patients with early symptoms of common cold and used self-diagnosis plus the presence of only one symptom to diagnose the common cold (24). The criticism that can be made against all of the studies illus- trated in Table 1 is that they all diagnose common cold by using different unvalidated scoring systems that are invented by each investigator, often with reference to Jackson scores to give the method of diagnosis some credibility. All the studies looking at an intervention such as a medicine recruit subjects within 36-48 hours of onset of symptoms and at this early stage a common cold is difficult to diagnose on the basis of symptoms, because symptoms are mild and few.

\section{Common cold: clinical entity or cultural concept?}

If the common cold is a clinical entity then it should be possible to define the disease in such a way that it can be confidently diagnosed. From the discussion above, it is apparent that there is no general agreement on how to diagnose a common cold using either symptomatology or virology. Figure 1 illustrates the relationship between viral infection of the upper airway and the symptoms that constitute a common cold. The viruses responsible for the common cold are shown as a list on the left of the diagram. All of these viruses can cause a syndrome of mild acute symptoms that will be self-diagnosed as a common cold. The range and severity of symptoms caused by infection with these viruses depends on the host response to the virus. An asymptomatic or sub-clinical infection is a common outcome, and when common cold viruses are circulating in the community it has been estimated that up to a third of the population may be infected without exhibiting any symptoms or only mild symptoms ${ }^{(25)}$. This population of mild symptoms is represented by the base area of the 'iceberg of infection' in Figure 1, and these subjects would not diagnose themselves as suffering from a common cold. If the infected subject is in any way immune deficient, due for example to chemotherapy, or steroid therapy, or poor nutritional status then the infection may cause severe and possibly life threatening disease that would not be called a common cold. Only when the symptoms are over the middle range of severity would they be diagnosed as a common cold, and even then, an increase in symptom severity could cause the diagnosis to be an 'influenza like illness' rather than a common cold. Rhinovirus infections can account for $25-50 \%$ of influ- 
enza-like illness ${ }^{(26)}$. The viruses may also cause more localised but common infections that will not be diagnosed by the patient or clinician as a common cold, such as: tonsillitis, pharyngitis, sinusitis, laryngitis, and otitis media.

The common cold syndrome is therefore only part of the spectrum of disease caused by common cold viruses, but it is a common syndrome that is readily self- diagnosed. The common cold is so common, that self-diagnosis is part of everyday culture. School children are estimated to have 7-10 colds a year and adults 2-5 colds a year (27), so with a conservative estimate of 3-4 colds a year any adult over 25 years of age will have experienced over 100 episodes of common cold, making the common cold syndrome a familiar part of life. In this respect, each patient is an expert on their own common cold syndromes, and the symptoms may vary from one cold episode to the next, so it is not possible to define the cold in any form of specific symptomatology. This variation in symptomatology is apparent in the duration of the illness. Figure 1 only gives a summary of the disease symptoms and does not relate them to any time course. Most definitions of a common cold refer to it as an acute disease and the term acute upper respiratory tract viral infection (URTI) is sometimes used to describe a common cold. But there is little agreement on what constitutes an acute common cold. In a study on school aged-children, $73 \%$ of 81 children continued to be symptomatic 10 days after onset of symptoms ${ }^{(28)}$. In a review on common cold, the mean duration of symptoms is reported to be 7-10 days "but a proportion of patients symptoms can still be present after 3 weeks" (14). The European position paper on rhinosinusitis and nasal polyps, (EPOS2012) discusses common cold as an acute rhinosinusitis and defines common cold as having a duration of less than 10 days ${ }^{(5)}$.

The common cold can therefore be viewed more as a cultural concept rather than a clinical entity, and the patient is more likely to be able to diagnose the disease rather than the clinician.

\section{Conclusion}

Clinical studies on common cold often give an appearance of some rigorous diagnosis of the syndrome on the basis of symptom scores, but these scoring systems have not been validated. Because of the familiarity of subjects with common cold and the variability in symptomatology, it seems a more reasonable approach to use self-diagnosis of common cold for clinical research studies and accept that the common cold is a cultural concept and not a clinical entity.

\section{Conflict of interest}

The author has no conflict of interest.

\section{REFERENCES}

1. Eccles R, Weber O. Preface. In: Eccles R Webber $\mathrm{O}$, editors. Common Cold. Basel: Birkhauser Verlag; 2009. p. ix-x.

2. Doyle W, Cohen S. Etiology of the com mon cold: Modulating factors. In: Eccles $\mathrm{R}$ Webber O, editors. Common Cold. Basel: Birkhauser Verlag; 2009. p. 149-186.

3. Common Cold. The Merck Manual. 17th edition ed. New Jersey: Merck Research Laboratories; 1999.

4. London: A \& C Black; 2002. Black's Medical Dictionary, 40th ed

5. Fokkens WJ, Lund VJ, Mullol J, Bachert C, Alobid I, Baroody F, et al. European Position Paper on Rhinosinusitis and Nasal Polyps 2012. Rhinol Suppl. 2012 23: 1-298.

6. Eccles R. Mechanisms of symptoms of common cold and flu. In: Eccles R, Webber O, editors. Common Cold. Basel: Birkhauser Verlag; 2009. p. 23-45

7. Jackson G, Dowling H, Spiesman I, Boand A Transmission of the common cold to volunteers under controlled conditions. 1 The common cold as a clinical entity. Arch Intern Med. 1958; 101: 267-278.

8. Tyrrell DA, Cohen S, Schlarb JE. Signs and symptoms in common colds. Epidemiol Infect. 1993; 111: 143-156.

9. Isaacs D. Clinical spectrum of disease in children. In: Myint S, Taylor-Robinson D, editors. Viral and other infections of the human respiratory tract. London: Chapman \& Hall; 1996. p. 47-60.

10. Evans AS, Kaslow RA, editors. Viral infections of humans. Epidemiology and control. 4th ed. New York: Plenum Medical Book Company; 1997

11. Weber $\mathrm{O}$. The role of viruses in the etiology and pathogenesis of common cold. In: Eccles R, Webber O, editors. Common Cold. Basel: Birkhauser Verlag; 2009. p. 107-147

12. Taylor JA, Weber WJ, Martin ET, McCarty RL, Englund JA. Development of a symptom score for clinical studies to identify children with a documented viral upper respiratory tract infection. Pediatr Res. 2010; 68: 252257.

13. Milstone AM, Perl TM, Valsamakis A Epidemiology of respiratory viruses in children admitted to an infant/toddler unit. Am J Infect Control. 2011; 40: 462-464.

14. Heikkinen T, Jarvinen A. The common cold Lancet. 2003: 361: 51-59.

15. Jordan WS, Jr. The mechanism of spread of Asian influenza. Am Rev Respir Dis. 1961; 83 (2)Pt 2: 29-40

16. Harvala $\mathrm{H}$, Mclntyre $\mathrm{CL}$, McLeish NJ Kondracka J, Palmer J, Molyneaux P, et al High detection frequency and viral loads of human rhinovirus species $A$ to $C$ in fecal samples; diagnostic and clinical implications. J Med Virol. 2012; 84: 536-542.

17. Chien JW Johnson JL. Viral pneumonias.
Epidemic respiratory viruses. Postgrad Med. 2000;107: 41-42, 5-7, 51-52.

18. Crowcroft N, Cutts F, Zambon M. Respiratory syncytial virus: an underestimated cause of respiratory infection, with prospects for a vaccine. Communicable Disease and Public Health. 1999; 2: 234-241.

19. El-Sahly HM, Atmar RL, Glezen WP, Greenberg SB. Spectrum of clinical illness in hospitalized patients with "common cold" virus infections. Clin Infect Dis. 2000; 31: 96-100.

20. Nakata A, Takahashi M, Irie M, Ray T, Swanson NG. Job satisfaction, common cold, and sickness absence among whitecollar employees: a cross-sectional survey. Ind Health. 2011; 49: 116-121.

21. Barrett B, Brown RL, Mundt MP, Thomas GR, Barlow SK, Highstrom AD, et al. Validation of a short form Wisconsin Upper Respiratory Symptom Survey (WURSS-21). Health Qual Life Outcomes. 2009: 7: 76.

22. Byun JS, Yang SY, Jeong IC, Hong KE, Kang W, Yeo $Y$, et al. Effects of So-cheong-ryongtang and Yeon-gyo-pae-dok-san on the common cold: randomized, double blind, placebo controlled trial. J Ethnopharmacol. 2011; 133: 642-646.

23. Yakoot M, Salem A. Efficacy and safety of a multiherbal formula with vitamin $C$ and zinc (Immumax) in the management of the common cold. Int J Gen Med. 2011; 4: 45-51. 
<smiles></smiles> 